\title{
Study on Interaction of Golf Expo and Golf Goods Industry Cluster
}

\author{
Liu Fangzhi* \\ P.E.College, Hunan University of International Economics, Changsha, China \\ 67604219@qq.com
}

\begin{abstract}
By using methods such as literature, taking Tangxia Golf Show, Tangxia golf goods industry cluster as an example, this paper discusses the relationship between the golf Expo and the golf goods industry cluster. This article holds that golf Expo is the engine for the development of golf goods industry cluster, golf goods industry cluster is the cornerstone of the development of golf Expo, the two complement each other, mutual promotion.
\end{abstract}

Index Terms - Golf Expo, Golf goods, Industrial Cluster, Tangxia

\section{Introduction}

Tangxia town is located in the southeast of Dongguan City, the town a total area of 128 square kilometers, 21 under the jurisdiction of the community, population 46000.It is not only the center town of Guangdong Province, but also one of the five strong towns in Dongguan City. Besides, it ranks fifth in Chinese thousand towns, its economic strength is in the forefront among these towns of Dongguan City. In recent years, Tangxia town takes advantage of Shenzhen Mission Hill, and vigorously develops the golf industry. From the last century 90's first golf enterprise settled in, the town of Tangxia has golf products manufacture and sales enterprises reached more than 140, its own brand products covered nearly 30 including golf clubs, ball head, ball sleeve, shirt, ball caps, shoes, a complete set of golf products. Ref. [1] All kinds of tax related to golf supplies excess more than a hundred million yuan, the total golf goods production of Tangxia accounts for nearly $40 \%$ of the world's golf goods production. Statistical data shows that 2012 1-10 month, GDP of big scale golf entrepreneurs reached about 18 hundred million yuan, year on year growth of $5.5 \%$. Golf exhibition is the "wind vane" for golf industry, and Tangxia town has successfully hosted the five international golf Expo since 2009. Now the town of Tangxia has initially formed one relatively complete industrial chain which include a set of golf products design, production, sales, trading. Therefore, the town has won the "Chinese golf industry town", "China golf industry base" title. it has typical significance for studying interaction of golf Expo and golf goods gndustry Cluster by taking Tangxia Golf Show, Tangxia golf goods industry cluster as an example.

\section{The Connotation of Golf Expo and Golf Goods Industry Cluster}

Golf Expo refers to in a certain region space, many people gathered together to form regular or irregular golf-related activities as a link conferences, exhibitions festivals, and tourism. Golf MICE industry is an emerging industry, an important branch of the sports exhibition industry. By organizing golf exhibition, a city not only can bring great social and economic benefits, but also enhance the brand image of the city, stimulating the development of related industries, to promote the harmonious development of society.

Ref. [2] Cai Baojia believes that industrial cluster is a geographical phenomenon in the evolution of the industrial development, namely a mutual association (complementary, competition) within the territory of enterprises and institutions in a certain geographical areas concentrated, forming organic system that structural integrity upper, middle and lower reaches (from raw material supply to distribution channels or end users),sound system peripheral support industrial, with features such as flexible. Ref. [3]Golf goods industry cluster is to golf goods industry as leading, dominated by many small and medium enterprises , associated enterprises, related institutions and the formation of a gathering economic community within a certain space. It is a important organizational form of the golf sporting goods industry towards intensification, specialization. TangXia Town has brought together a large number of golf goods companies, and has formed a industrial chain within production, supply, marketing and other related facilities, it is a typical golf goods industry cluster base in our country.

\section{Golf Expo is the Engine for the Development of Golf Goods Industry Cluster.}

\subsection{It sets up the show stage for golf goods Industrial cluster}

Tangxia golf show is the significant platform which promotes the internal and external communication of the golf industry. It is also a platform that shows golf enterprise images and golf goods. Since the fifth Golf show successfully held in Tangxia, it becomes increasingly important for local golf goods enterprise, and plays an extremely important role in promoting the Tangxia golf industry more bigger and stronger.

Author introduction *: Liu Fangzhi (1980 -), female, Henan Xiping, master, lecturer, research direction: physical education and sports culture

Foundation item: Hunan Provincial Department of education science research project (11C0769); the national characteristic specialty project funded construction (TS12332) 
With the help of golf Expo, Tangxia local golf enterprise bring forth the new through the old products, to promote the brand. Its local brands gradually hold the status, and become extensively be well kown and accepted by people. For example, Tangxia launched a golf brand "Tangxia Golf" in the 2012 Tangxia golf show."Tangxia Golf" is the continuation of the "CTGG" product advantages, based on the fusion of golf the latest design elements, made from the world's top golf material. It is the distillation of "CTGG". Ref. [4]Officials in the Tangxia informed that "Tangxia Golf" was made by a collection of 12 domestic golf enterprise efforts, Tangxia town government led and funded, covered ball bag, clubs, ball sleeve shirt, a complete set of golf products. The local brands of Tangxia golf have beome a beautiful scenery in this golf show. In addition, it promotes exchanges, and show the unique charm of Tangxia golf sports goods industry cluster for communication, negotiation, friendship, communication of information of the local golf enterprise and personage of industry inside and outside.

\subsection{Comprehensively promote the golf goods industry cluster brand effect}

The successful organization of Tangxia golf show rapidly improved Tangxia "Chinese golf industry town", "China's golf industry base" fame. With the large number of media reports, exhibitors and the audience are more and more. This improved the of reputation of the brand of golf goods Industrial Cluster of Tangxia, and expanded the Tangxia foreign influence. The Golf Show had been held in the "factory gate" by Tangxia, its purpose is that it goes without saying. On Golf Show, if exhibitors or buyers want to grasp enterprise production process, they can visit into the factory immediately, and this is the advantage of Tangxia Golf Show. the brand of golf goods industrial cluster of Tangxia begin to exert its effect, the best interpretation is the number of exhibitors, which there are more than 20 million exhibitors of five consecutive Golf Show .

\subsection{The economic impacts of golf goods industrial cluster}

Exhibition economy is considered to be low-cost, highincome, high-profit industries, and it has a strongly effect of industrial mobilization and industrial agglomeration. According to statistics, the coefficient of industry led international exhibition industry is about 1:9, the exhibition venues if the income is 1, related social income 9. Exhibition economy is the industry of driving tourism, commerce, logistics, communications, catering, accommodation and other multi-beneficiary. Tangxia Golf Show brings opportunities for hotels, restaurants, transportation, commerce, advertising, decoration and other industries, and promotes the prosperity of the town of tertiary industry. Ref. [5]According to thestatistics, during the first Tangxia golf show, it received a total of more than3,000 professional buyers at home and abroad, and over 10 million guests. Among them, the participating enterprises and domestic and foreign merchants were signed more than 3000 cases of contract, on-site turnover of 210millionRMB, the intention to turnover reached 350millon RMB. Ref. [6]During the Second Tangxia golf show of, there were nearly 300 golf exhibitors, and 680 booths, attracting U.S, Europe, Japan, Korea, Southeast Asia and more than 11,000merchants across the country to visit and purchase, the number of more than110,000 visitors participated in, then it had turnover directly of 280 millionyuan, and turnover intention of 700 million yuan. All in all, it can be described as merchants gathered, almost a full house, unprecedented, and achieve good effects expected.

\subsection{It provides a wealth of information and technology for golf goods industry cluster}

Science and technology is the first productivity, the development of golf goods industry cluster relies on information technology services. Tangxia golf show provides a wealth of information and technical resourcesfor golf goods industrial cluster. Golf Expo attracted a large number of golf industry, they bring the domestic golf market new information on the development of the industry, cutting-edge technology, effectively accelerate the golf industry material flow, commodity flow, information flow. Meanwhile, exhibitors through trade negotiations, understanding and mining the current domestic and international golf goods market trends and sales hotspot, be ready for future development, production and sales of market demand for the product; the colleges and universities scientific research institutions participating and high-end BBS ,has brought a series of new achievements, new technology, new information; that have a far-reaching influence for the sustainable development of golf industry transformation in Tangxia.

\section{Golf Goods Industry Cluster is the Cornerstone of the Development of Golf Expo}

\subsection{Promote the golf Expo scale more bigger}

Tangxia golf goods industry cluster promote the expansion of the scale of Tangxia golf show. Since the 1990s, the number of Tangxia golf enterprise is more than 140 now, their production and sales of golf goods are from soup to nuts and wide varieties. With the increase in exhibitors and the increase of golf goods category, the scale of Tangxia golf show is also expanding, this is evidenced by exhibition position increased year by year. From the initial, countless local enterprise holded more than a dozen products to golf show, today businessmen spread all over at home and abroad. From alone to cluster development, from the initial low-end OEM to embarked on the path of brand development today, the scale of Tangxia golf show is enlarged. 2013Tangxia golf show was expanded the scale of the exhibition, compared with 2011, added more than 100 booths, a total of 577 which reached a historical high.

\subsection{Ascension of influence of golf Expo}

Tangxia golf goods industry cluster led to the birth of Tangxia golf golf show. Ref. [7]The first Tangxia golf show, local golf enterprises were engaged in OEM, they faced such 
problems as lack of innovation and the comprehensive competitiveness. Tangxia Town, the related person in charge said that the amount of Tangxia golf industry is although relatively large, but can only be considered "primary scale". The exhibition area of the 2 nd Tangxia golf show expanded to 18000 square meters, more than the first half, Tangxia was widly recognized and praised in golf industry at home and abroad, it has won the "Chinese famous town of the golf industry", "Chinese golf industry base" honorary title. With the Tangxia golf show continuous development, its operation mechanisms continue to improve continuously, more and more "internationalization, specialization, marketization, and brand", its visibility and reputation grow with each passing day. Ref. [8] It has developed important trade platform in golf industry at present and it's also China's most influential golf SanDa one exhibition.

\subsection{Promote the golf Expo to function more professional and humanized.}

Tangxia Golf Expo in general is sponsored by the people's Government of Dongguan City, Tangxia town of Dongguan City Sports Bureau, Dongguan City Golf Association, co-organized by the Tangxia Commercial Association, Tangxia Town Golf Industry Development Office, Dongguan Mission Hills Golf Club and Dongguan Golf Association contractor. It is a exhibition which government, golf products producers, golf club, golf enthusiasts, media participation in. With the brand promotion of Tangxia Golf, its mode of operation is more and more professional, more humane. Take the fifth 2013Tangxia Golf Expo for instance, Ref. [9] the Committee of Golf show selected exhibitor by various forms of selection so as to strive to the participating enterprises which are well-known; perfect
VI system and collect mascot were perfected, the brand image was enhanced; professional forum was held; to create intelligent service platform, strengthening the exhibition services; "Tangxia Cup" National Golf Invitational Exhibition was held; many activities were held. In addition to golf goods exhibition, Committee of Golf show also arranged various features performances and activities, such as professional coach free course teaching, models, dance, Live band tour show, magic show around the golf theme activities. In addition, in the second Tangxia golf show, in order to set up an important platform closely linked, the organizing committee introduced a special golf exchange website online sales, breaking the traditional exposition time and space limitations, so that exhibitors not subject to site size and the time limit, the exhibition information sharing of global enterprise products exhibition, global, more make this site a "never ending" the Tangxia golf show.

\section{References}

[1] http://sports.sina.com.cn/golf/2013-11-13/10326882904.shtml.

[2] Cai Baojia, "The empirical study on regional sports goods Industry Cluster," Journal of Shanghai Physical Educate Institute, vol. 30, no. 1, pp. 31-34, January 2006.

[3] Yang Ming, Guo Liangkui et al, "Study on the development of sports goods Industry Cluster and government policy in China," Sports and science, vol. 28, no.3, pp. 27-31, March 2007.

[4] Dong Zhe, "Golf show achieves 200million yuan," Guangzhou Daily, 2012-11-05(DGA15)

[5] http://2012.tangxiagolfshow.org/publicfiles/business/htmlfiles/txgolfshow /s34964/201209/552140.htm.

[6] http://2012.tangxiagolfshow.org/publicfiles/business/htmlfiles/txgolfshow /s34969/201209/552138.htm.

[7] http://news.hexun.com/2013-11-14/159674269.html.

[8] http://www.chinadaily.com.cn/hqgj/jryw/2013-1115/content_10593562.html.

[9] http://news.sina.com.cn/o/2013-11-15/072028716641.shtml. 